\title{
Substance Use in Adolescents 10 Years After the World Trade Center Attacks in New York City
}

\author{
Lisa M. Gargano ${ }^{a}$, Alice E. Welch ${ }^{a}$, and Steven D. Stellman ${ }^{a, b}$ \\ ${ }^{\mathrm{a}}$ New York City Department of Health and Mental Hygiene, Long Island City, NY, USA; ${ }^{\mathrm{b}}$ Columbia University, New York, NY, USA
}

\begin{abstract}
We examined prevalence of and factors associated with substance use 10 to 11 years post-9/11 among adolescents in the World Trade Center Health Registry. Logistic regression analyses showed that adolescents who witnessed a disturbing event on 9/11 were twice as likely to report ever drinking and almost three times as likely to have ever used marijuana. Among those $\geq 5$ years of age on $9 / 11$, fear for personal safety on 9/11 was significantly associated with having ever smoked cigarettes, ever drank, and ever used marijuana. Intervention and education for adolescents particularly focused on substance use and coping strategies may be warranted after large-scale disasters.
\end{abstract}

\section{KEYWORDS}

adolescents; substance use;

World Trade Center

\section{Introduction}

An estimated 25,000 children under 18 years of age were living or going to school in lower Manhattan near the World Trade Center (WTC) on September 11, 2001 (9/11), with tens of thousands more children in the path of the massive dust cloud and smoke that resulted from the collapse and destruction of the WTC towers and other nearby structures (Thomas et al., 2008). Studies of adults after the WTC attacks found small, but statistically significant, exposure-related increases in the use of cigarettes, alcohol, and marijuana (Adams, Boscarino, \& Galea, 2006; Boscarino, Adams, \& Galea, 2006; Vlahov, Galea, Ahern, Resnick, \& Kilpatrick, 2004; Vlahov et al., 2002; Welch et al., 2014). Studies have shown that experiencing trauma at an early age increases the risk of substance abuse later in life (Clark, Lesnick, \& Hegedus, 1997; Giaconia et al., 2000; Perkonigg, Kessler, Storz, \& Wittchen, 2000). In addition, the literature suggests that just as in adults, a reciprocal relationship exists such that adolescents who abuse substances are at a significantly higher risk for experiencing trauma and developing posttraumatic stress disorder (PTSD; Clark et al., 1997; Giaconia et al., 2000; Perkonigg et al., 2000). Adolescents experiencing both traumatic stress and substance abuse problems also suffer greater impairments in psychological, social, physical, and academic functioning (Giaconia et al., 2000).
Few studies have assessed the relationship between 9/11 exposure and risk behaviors, such as substance, tobacco, and alcohol use, in adolescents. A study of New York City (NYC) high school students six months after the WTC attack found that increased drinking was associated with direct exposure to the attack (Wu et al., 2006). Chemtob, Nomura, Josephson, Adams, and Sederer (2009) found that adolescents with one WTC exposure risk factor had a fivefold increase in substance use, while those with three or more exposure risk factors had a nearly 19 -fold increase.

Adolescence is the peak time of initiation of substance use. Early onset use of alcohol, tobacco, and other drugs is associated with increased risk of substance use, abuse, and dependence in adulthood. Thus, any substance use among adolescents is a major concern (Centers for Disease Control and Prevention, 2014a, 2015; Grant \& Dawson, 1997; Grant, Stinson, \& Harford, 2001). Youths who consume alcohol are more likely to have social school, legal, and physical health problems, as well as increased risk for injury and death (e.g., suicide, homicide, and accidents; Centers for Disease Control and Prevention, 2014a). Moreover, substance use in youth has been shown to affect educational achievement (Staff, Patrick, Loken, \& Maggs, 2008) and has been significantly associated with diminished educational achievement, as measured by grade point average and

CONTACT Lisa M. Gargano $\triangle$ Igargano1@health.nyc.gov E MPH 42-09 28th Street, 7th Floor, Long Island City, NY 11101. We are thankful to Kimberly Caramanica, Pauline Thomas, Charon Gwynn, and Jim Hadler for their critical review of this article. 
highest educational degree received (McLeod, Uemura, \& Rohrman, 2012). In addition, the negative impact of substance use was increased when co-occurring with other mental health problems (McLeod et al., 2012). A study of 9/11-exposed adolescents showed that an increase in substance use was associated with impaired school work, school behavior, and grade level (Chemtob et al., 2009).

In the foregoing studies, substance use in adolescents was measured after relatively short periods of time (six months to 18 months) post-exposure; little is known about factors that may be associated with increased risk of substance use 10 to 11 years after 9/11. Given that early onset substance use among adolescents has negative consequences in both the short and long term, it is important to understand factors that may influence early substance use among exposed adolescents. We assessed relationships between exposure to 9/11 and later adolescent behaviors by examining (a) the prevalence of substance use (cigarette smoking, drinking, and marijuana use) among adolescents' ages 10 to 18 years who were exposed to the WTC attack 10 to 11 years earlier, and (b) whether PTSD, behavior problems, and WTC exposures are associated with substance use.

\section{Methods}

\section{Study population and procedure}

Participants were drawn from enrollees in the World Trade Center Health Registry (hereafter referred to as the Registry), a longitudinal cohort of 71,430 rescue and recovery workers; lower Manhattan residents living south of Canal Street; and schoolchildren, building occupants, or passersby south of Chambers Street on September 11, 2001 (Brackbill et al., 2009). Baseline data were collected from 2003-2004 (Wave 1) and follow-up data were collected in 2006-2008 (Wave 2) and 2011-2012 (Wave 3). Children and teenagers less than 18 years of age on 9/11 were recruited for the Registry through their parents and active outreach to schools and community organizations. The Registry contacted 37 schools south of Canal Street in Manhattan, including child care centers, nursery schools, and public and private schools with grades kindergarten through 12 by mail and telephone. Registry staff presented information about the Registry to teacher and parent groups. The NYC Department of Education endorsed the Registry project to families of 12,600 public school children through mailed letters and nine private schools provided lists of student names (Murphy et al., 2007).

Children were eligible for Registry enrollment if they resided or attended school in Manhattan south of Canal
Street or were present south of Chambers Street on the morning of 9/11 (Thomas et al., 2008). The Registry protocol was approved by the institutional review boards of the Centers for Disease Control and Prevention and NYC Department of Health and Mental Hygiene. Informed consent or assent was obtained from all individual participants included in the study.

\section{Study sample}

Adolescents completed surveys that included assessment of substance use and screenings for PTSD and behavioral problems. Parents completed a separate survey on adolescent 9/11 exposures, household characteristics, and additional health factors on the adolescent. Adolescents were included in this analysis if they were 10 to 18 years of age at time of the Wave 3 survey. The response rate for adolescents at Wave 3 was $36.6 \%(491 / 1,341)$. Adolescents who did not complete Wave 3 were similar to those who did with regard to age at 9/11, sex, parent education, and all 9/11 exposures. However, using chi-square tests there was a significantly greater proportion of White than Black or Hispanic adolescents among those completing the survey $(p<0.0001)$ as well as a greater proportion of those whose parents reported a 2002 income of less than $\$ 50,000$ ( $p=$ 0.01). Adolescents who did not have a corresponding parent survey completed were excluded from this analysis $(N=19)$. This resulted in a final sample size of 472 .

\section{Demographic characteristics}

We included demographic variables that were previously found to be associated with post-9/11 substance use in high school students: age (at time of survey), sex, and race/ethnicity of the adolescent (Wu et al., 2006). We also included parent education and household income from the parent survey.

\section{Substance use}

At Wave 3, adolescents were asked if they ever smoked cigarettes, currently smoked cigarettes, ever had a drink of alcohol, drank in the past 30 days, had five or more drinks of alcohol in a row within a couple of hours in the past 30 days, ever tried marijuana, used marijuana in the past year, and used marijuana in the past 30 days.

\section{Measures}

\section{9/11 Experiences}

Adolescent 9/11-related exposures were assessed using information from the adolescent's Wave 1 questionnaire as reported by a parent proxy, the Wave 3 parent 
questionnaire, and the Wave 3 adolescent questionnaire. Direct exposures were assessed separately at Wave 1 and included the following: (a) witnessed one or more disturbing events during and/or after the WTC attacks (airplane crashing into a tower, buildings collapsing, people running away from a cloud of smoke, or people being injured, killed, falling, or jumping from one of the towers), (b) sustained an injury as a result of the attacks (burn, broken bone, concussion, cut, sprain, or other injury), and (c) caught in the dust cloud that resulted from the collapse of the WTC towers. Indirect or family exposure was collected on the Wave 3 parent questionnaire and defined as having a family member (mother, father, sibling, grandparent, or any other family member) who was injured or killed in the attacks or was in the WTC attack area and escaped unhurt. In a subset of Wave 3 adolescents who were five years of age or older at 9/11, we assessed adolescent-reported fear for personal safety and/or safety of loved ones on 9/11on the Wave 3 adolescent questionnaire.

\section{Diagnostic Interview Schedule for Children (DISC) Predictive Scale (DPS)}

The Diagnostic Interview Schedule for Children (DISC) Predictive Scale (DPS) was used to screen for PTSD in adolescents. This tool has previously been used to study the prevalence of probable mental health disorders among NYC public school students six months following the WTC attack (Hoven et al., 2005). The DPS was modified from a structured diagnostic interview, the National Institute of Mental Health's DISC Version IV; it incorporated the DISC items that were most predictive of the Diagnostic and Statistical Manual of Mental Disorders (DSM-IV) PTSD diagnosis, resulting in a sensitivity of $85 \%$ and a specificity of $98.4 \%$ (Hoven et al., 2005; Lucas et al., 2001; Shaffer, Fisher, Lucas, Dulcan, \& Schwab-Stone, 2000).The assessment for PTSD in adolescents included eight 9/11-related stress symptom questions and an additional six questions evaluating stress-related functioning of the adolescent. Adolescents answered the stress-related functioning questions during the past four weeks as "not at all," "hardly ever," "some of the time," and "a lot of the time." Adolescents were considered to have probable PTSD (hereafter referred to as PTSD) if they had a score of 9 or greater on the functioning questions and if they answered "yes" to five of the eight symptom questions suggesting reexperiencing, avoidance, or sense of a foreshortened future (Hoven et al., 2005). The reliability of the DPS was measured using Cronbach's alpha and was found to have high internal consistency of $\alpha=0.97$ ).

\section{Strengths and Difficulties Questionnaire (SDQ)}

Adolescents completed the Strengths and Difficulties Questionnaire (SDQ), a brief behavioral screening questionnaire that asks about 25 attributes (both positive and negative) that are divided among five scales of five items each, creating domain scores for conduct problems, hyperactivity, emotional symptoms, peer problems, and prosocial behavior. A total difficulties score $(0-40)$ was computed by adding scores from the four problem subscales (conduct, hyperactivity, emotional, and peer problem domains). The domains were scored as normal, borderline, and abnormal based on normative U.S. data. For this analysis, we created a dichotomous variable for the SDQ by combining borderline and abnormal SDQ scores into one group borderline/abnormal (16-40) and normal (0-15) (Bourdon, Goodman, Rae, Simpson, \& Koretz, 2005). The SDQ total difficulties score has been shown to be a psychometrically sound measure of child mental health problems (Goodman, Ford, Simmons, Gatward, \& Meltzer, 2000; Richter, Sagatun, Heyerdahl, Oppedal, \& Roysamb, 2011) and correlates with existing questionnaire and interview measures. It is also associated with increasing rates of clinician-rated diagnoses of child mental disorders across its full range (Goodman, Lamping, \& Ploubidis, 2010).

\section{School functioning}

The five items from the School Functioning Scale from the Pediatric Quality of Life Inventory Version ${ }^{\mathrm{TM}} 4.0$ (PedsQL ${ }^{\mathrm{TM}}$ 4.0) were used in this analysis. This scale measures the extent to which health-related issues may impact school functioning. For the purposes of this investigation, the 5-point child self-report scale for ages eight to 18 was utilized. Enrollees were asked to rate how much of a problem each item has been during the past month (never a problem; almost never a problem; sometimes a problem; often a problem; almost always a problem). Items on the School Functioning Scale assess difficulty paying attention in class, forgetting things, keeping up with school, missing school because of not feeling well, and missing school because of medical appointments and hospitalizations. Scale scores are computed as the sum of the items divided by the number of items answered. If more than half of the items in the scale are missing, the scale score is not computed (Fairclough, 2002; Varni, Burwinkle, \& Seid, 2006). This accounts for the differences in sample sizes for scales reported. Although there are other strategies for imputing missing values, this computation is consistent with previous PedsQL ${ }^{\mathrm{TM}}$ peer-reviewed publications as well as other well-established Health-Related Quality of Life (HRQOL) measures (Fairclough \& Cella, 1996; Ware, 1993). The reliability of the School Functioning Scale was measured using Cronbach's alpha and was found to have high internal consistency of $\alpha=0.86$. School functioning was treated as a continuous variable in the analyses. 


\section{Parent mental health problems}

Parent non-specific psychological distress (NPD) symptoms were measured using the Kessler 6 (K6) scale, a validated tool which measures psychological symptoms in the past 30 days. The $\mathrm{K} 6$ consists of six items scored on a scale of 1 (not at all) to 5 (extremely), with scores ranging from 0 to 24. Severe NPD was defined as a score of $\geq 12$ (Kessler et al., 2002). The reliability of the K6 was measured using Cronbach's alpha and was found to have high internal consistency of $\alpha=0.92$.

\section{Other trauma and health care services}

Adolescents were asked, not including the WTC attacks, if they were ever seriously hurt, thought they might be killed, or had something happen to them that was deeply disturbing (Yes/No). Parents were asked if their adolescent had received any treatment or counseling from a mental health professional in the past 12 months and if since 9/11/2001 their adolescent had received any treatment or counseling for substance use (Yes/No).

\section{Statistical analyses}

Univariate and bivariate analyses were conducted to describe the demographic, mental health, 9/11 exposures, and substance use of the study population. Multivariable logistic regression was used to estimate associations between witnessing disturbing events on 9/11, school functioning, fear for personal safety on $9 / 11$ (for those $\geq 5$ years old on 9/11), and substance use, adjusting for demographic variables that were significantly associated with substance use in bivariate analyses. All analyses were conducted using SAS Version 9.2 (Cary, NC).

\section{Results}

\section{Demographics of study population}

The study population consisted of 235 (49.8\%) males and $237(50.2 \%)$ females (Table 1). The majority of respondents were age 10 to 15 years (66.3\%) and White (53.6\%). Most parents reported having attended at least some college (85.2\%) and a household income of greater than $\$ 75,000$ (62.6\%). More than half of adolescents witnessed disturbing events on 9/11 (57.8\%), 201 (42.6\%) were caught in the dust cloud, and only 27 (5.7\%) sustained an injury. Of the 472 adolescents, 55 (12.0\%) adolescents had abnormal/ borderline SDQ scores and $13(2.8 \%)$ had PTSD (Table 1).

\section{Substance use in adolescents exposed to 9/11}

Overall, 10.8\% of adolescents reported ever having smoked (Table 2). Of those who ever smoked, 3.9\% reported
Table 1. Demographic Characteristics.

\begin{tabular}{|c|c|}
\hline Demographics & Wave 3 No. (\%) \\
\hline Total & 472 \\
\hline \multicolumn{2}{|l|}{ Adolescent Demographics } \\
\hline \multicolumn{2}{|l|}{ Sex } \\
\hline Male & $235(49.8)$ \\
\hline Female & $237(50.2)$ \\
\hline \multicolumn{2}{|l|}{ Age at interview (years) } \\
\hline $10-15$ & $266(66.3)$ \\
\hline 16-18 & $135(33.7)$ \\
\hline \multicolumn{2}{|l|}{ Race/Ethnicity } \\
\hline White & $253(53.6)$ \\
\hline Black & $25(5.3)$ \\
\hline Hispanic & $49(10.4)$ \\
\hline Asian/Multiracial/Other & $145(30.7)$ \\
\hline \multicolumn{2}{|l|}{ Parent Demographics } \\
\hline \multicolumn{2}{|l|}{ Education } \\
\hline High school graduate or less & $65(14.8)$ \\
\hline Some college or higher & $374(85.2)$ \\
\hline \multicolumn{2}{|l|}{ Household income } \\
\hline$\leq \$ 75,000$ & $166(37.4)$ \\
\hline$>\$ 75,000$ & $278(62.6)$ \\
\hline \multicolumn{2}{|l|}{ Adolescent Exposures } \\
\hline \multicolumn{2}{|l|}{ Witnessed $\geq 1$ disturbing events } \\
\hline Yes & $273(57.8)$ \\
\hline No & $199(42.2)$ \\
\hline \multicolumn{2}{|l|}{ Sustained injury on $9 / 11$} \\
\hline Yes & $27(5.7)$ \\
\hline No & $445(94.3)$ \\
\hline \multicolumn{2}{|l|}{ Caught in dust cloud on $9 / 11$} \\
\hline Yes & $201(42.6)$ \\
\hline No & $271(57.4)$ \\
\hline \multicolumn{2}{|l|}{ Family exposure } \\
\hline Yes & $162(34.3)$ \\
\hline No & $310(65.7)$ \\
\hline \multicolumn{2}{|l|}{ Parent mental health } \\
\hline $\mathrm{K} 6 \geq 12$ & $56(11.9)$ \\
\hline $\mathrm{K} 6<12$ & $413(88.1)$ \\
\hline \multicolumn{2}{|l|}{ Other trauma (not 9/11) } \\
\hline Yes & $69(15.3)$ \\
\hline No & $383(84.7)$ \\
\hline \multicolumn{2}{|c|}{ Adolescent Health Care } \\
\hline \multicolumn{2}{|c|}{ Treatment by a mental health professional (past 12 months) } \\
\hline Yes & $87(19.1)$ \\
\hline No & $368(80.9)$ \\
\hline \multicolumn{2}{|c|}{ Treatment or counseling for substance use (since $9 / 11 / 01$ ) } \\
\hline Yes & $11(2.4)$ \\
\hline No & 439 (97.6) \\
\hline \multicolumn{2}{|l|}{ Adolescent Screening Measures } \\
\hline \multicolumn{2}{|l|}{ SDQ } \\
\hline Abnormal/borderline & $55(12.0)$ \\
\hline Normal & $402(88.0)$ \\
\hline \multicolumn{2}{|l|}{ PTSD } \\
\hline Yes & $13(2.8)$ \\
\hline No & $459(97.2)$ \\
\hline School functioning (mean $[S D]$ ) & $76.5(17.5)$ \\
\hline
\end{tabular}

Note. SDQ $=$ Strengths and Difficulties Questionnaire.

smoking every day and 9.8\% reported smoking some days. Eighteen percent of adolescents reported ever having drunk. Of those, $54.7 \%$ reported drinking in the past 30 days and $12.8 \%$ reported having more than five drinks in a row in the past 30 days. Almost $10 \%$ of adolescents reported having ever used marijuana. Of those, $93.5 \%$ reported using marijuana in the past year and $60.9 \%$ reported using marijuana in the past 30 days (Table 2). Overall, at Wave 3 , 46 adolescents only had one risk behavior, 16 reported two, and 35 reported three (data not shown). 
Table 2. Prevalence of Adolescent Substance Use.

\begin{tabular}{|c|c|c|c|}
\hline \multirow[b]{2}{*}{ Substance } & \multicolumn{3}{|c|}{ Wave 3 2011-2012 } \\
\hline & $N$ & $\begin{array}{l}\% \text { out } \\
\text { of total }\end{array}$ & $\begin{array}{c}\% \text { out of } \\
\text { those who ever }\end{array}$ \\
\hline \multicolumn{4}{|l|}{ Smoking } \\
\hline Ever smoked & 51 & 10.8 & - \\
\hline \multicolumn{4}{|l|}{ Currently smoke } \\
\hline Every day & 2 & 0.4 & 3.9 \\
\hline Some days & 5 & 1.1 & 9.8 \\
\hline \multicolumn{4}{|l|}{ Drinking } \\
\hline Ever drank & 86 & 18.2 & - \\
\hline Drank in the past 30 days & 47 & 10.0 & 54.7 \\
\hline $\begin{array}{l}\text { More than } 5 \text { drinks in } \\
\text { a row in past } 30 \text { days }\end{array}$ & 11 & 2.3 & 12.8 \\
\hline \multicolumn{4}{|l|}{ Marijuana } \\
\hline Ever used & 46 & 9.7 & - \\
\hline Used in the past year & 43 & 9.1 & 93.5 \\
\hline Used in the past 30 days & 28 & 5.9 & 60.9 \\
\hline
\end{tabular}

\section{Factors associated with substance use}

Older adolescents were more likely than younger adolescents to have ever tried any one of the substances (Table 3). Asian/multiracial/other adolescents were less likely than White adolescents to ever have tried any of the substances. Ever having smoked was associated with having witnessed disturbing events on 9/11 only in the unadjusted analysis; after adjustment the odds ratio (aOR) was 1.8 (95\% CI: 0.8-4.0). Adolescents who had witnessed a disturbing event on 9/11 were more than twice as likely to report ever having drank (aOR: 2.1; 95\% CI: 1.1-4.3) and almost three times as likely to ever having used marijuana (aOR: 2.7; 95\% CI: 1.16.4). Each unit increase in school functioning was associated with a $3 \%$ decrease in the odds of ever having smoked (aOR: 0.97; 95\% CI: 0.95-0.99), a 2\% decrease in the odds of ever having drank (aOR: 0.98; 95\% CI: $0.97-0.99)$, and a $4 \%$ decrease in the odds of ever having used marijuana (aOR: 0.96; 95\% CI: 0.95-0.99; Table 3). SDQ score, PTSD, parent mental health, other trauma (not 9/11), or having received treatment or counseling for substance use were not significantly associated with any substance use in the adjusted models. Having received treatment by a mental health professional in the past 12 months was only associated with substance use in the unadjusted models, with those having received treatment more likely to ever have tried each of the three substances. In a subset analysis of adolescents who were five years of age or older on 9/11 $(N=174)$, fear for safety of loved ones on $9 / 11$ was not associated with substance use, while fear for personal safety on $9 / 11$ was significantly associated with ever having smoked cigarettes (aOR 2.7; 95\% CI: 1.1-7.4), drunk (aOR: 3.3; 95\% CI: 1.2-8.7), and used marijuana (aOR: 2.7; 95\% CI: 1.1-7.2; Table 3).

\section{Discussion}

In this study of adolescent behavior 10 to 11 years after 9/11, we found that while overall adolescent substance use was low, 9/11 experiences such as witnessing disturbing events or fear for personal safety on 9/11 were significantly associated with substance use. Only a small number of prior studies have directly assessed 9/11exposed adolescent responses to risk behaviors and mental health factors (Chemtob et al., 2009; Hoven et al., 2005; Wu et al., 2006) and none of these studies report on the long-term impact of 9/11-exposed adolescents. Our findings show a lower prevalence of report of substance use compared to national reports of substance use among high school-aged adolescents from the Youth Risk Behavior Surveillance System (YRBSS; Centers for Disease Control and Prevention, 2014b); however, similar to trends in the YRBSS, we observed the largest percentage of adolescents reported ever having drank, followed by ever having smoked cigarettes, and the smallest percentage ever having tried marijuana. Since two-thirds of our population is younger (age 10 to 15 years), our numbers more closely resemble YRBSS data on middle school-aged adolescents (Centers for Disease Control and Prevention, 2014b).

Similar to other studies conducted more proximate to the attacks (Chemtob et al., 2009; Wu et al., 2006), we found that having the direct exposure of witnessing disturbing events on $9 / 11$ was associated with substance use. A more subjective measure of exposure assessed at Wave 3 (fear for personal safety) was significantly associated with substance use; however, since recall of this type of emotion may not be valid in children who were under five years of age at time of event, analysis of these questions was limited to those adolescents who were over age five on 9/11. Our findings are consistent with previous work on exposure to terrorism among Israeli youths, which demonstrated an association between adolescent alcohol consumption and both physical and psychological (i.e., knowing someone who was killed or injured) proximity to a terrorist attack, suggesting that adolescents may, in fact, be using alcohol or other drugs as a coping strategy (Schiff et al., 2006).

Substance use problems can often involve school avoidance and declining academic performance (Hawkins, Catalano, \& Miller, 1992). Despite the use of different instruments, our results are consistent with Chemtob and colleagues, who found that increased substance use was an important predictor of impairment in school functioning (Chemtob et al., 2009). Our study is the first to use the School Functioning Scale from the PedsQL ${ }^{\mathrm{TM}} 4.0$ to assess its association with substance use on 9/11-exposed adolescents. In the present study, mean 
Table 3. Factors Associated With Substance Use Among Adolescents at Wave 3 (2011-2012).

\begin{tabular}{|c|c|c|c|c|c|c|c|c|c|}
\hline & \multicolumn{3}{|c|}{ Ever Smoke } & \multicolumn{3}{|c|}{ Ever Drink } & \multicolumn{3}{|c|}{ Ever Marijuana } \\
\hline & $\begin{array}{c}\text { Total } \\
\text { No. }(\%)^{a}\end{array}$ & $\begin{array}{c}\text { COR } \\
(95 \% \mathrm{Cl})\end{array}$ & $\begin{array}{c}\mathrm{aOR} \mathrm{R}^{\mathrm{b}} \\
(95 \% \mathrm{Cl})\end{array}$ & $\begin{array}{c}\text { Total } \\
\text { No. }(\%)^{\mathrm{a}}\end{array}$ & $\begin{array}{c}\text { cOR } \\
(95 \% \mathrm{Cl})\end{array}$ & $\begin{array}{c}\mathrm{aOR} \mathrm{R}^{\mathrm{b}} \\
(95 \% \mathrm{Cl})\end{array}$ & $\begin{array}{c}\text { Total } \\
\text { No. }(\%)^{a}\end{array}$ & $\begin{array}{c}\text { cOR } \\
(95 \% \mathrm{Cl})\end{array}$ & $\begin{array}{c}\mathrm{aOR} \mathrm{R}^{\mathrm{b}} \\
(95 \% \mathrm{Cl})\end{array}$ \\
\hline \multicolumn{10}{|l|}{ Adolescent demographics } \\
\hline \multicolumn{10}{|l|}{ Gender } \\
\hline Males & $26(11.5)$ & $1.1(0.6-1.9)$ & - & 37 (16.2) & $0.7(0.5-1.2)$ & - & $23(10.0)$ & $1.0(0.6-1.9)$ & - \\
\hline Female & $25(10.8)$ & REF & - & $49(21.3)$ & REF & - & $23(10.0)$ & REF & - \\
\hline \multicolumn{10}{|l|}{ Age at interview (years) } \\
\hline $10-15$ & $12(4.6)$ & REF & REF & $17(6.6)$ & REF & REF & $7(2.7)$ & REF & REF \\
\hline $16-18$ & $33(24.6)$ & $\begin{array}{c}6.8 \\
(3.4-13.7)^{*}\end{array}$ & $\begin{array}{c}7.0 \\
(3.2-15.1)^{*}\end{array}$ & $58(43.6)$ & $\begin{array}{c}11.0 \\
(6.1-20.1)^{*}\end{array}$ & $\begin{array}{c}12.2 \\
(6.2-24.4)^{*}\end{array}$ & $35(26.1)$ & $\begin{array}{c}12.8 \\
(5.5-29.7)^{*}\end{array}$ & $\begin{array}{c}13.4 \\
(5.3-33.7)^{*}\end{array}$ \\
\hline \multicolumn{10}{|l|}{ Race/Ethnicity } \\
\hline White & $34(13.9)$ & REF & REF & $56(22.9)$ & REF & REF & $33(13.4)$ & REF & REF \\
\hline Black & $5(20.0)$ & $1.5(0.5-4.4)$ & $2.3(0.7-8.3)$ & $4(16.0)$ & $0.6(0.2-1.9)$ & $0.6(0.1-2.6)$ & $2(8.0)$ & $0.5(0.1-2.5)$ & $0.5(0.1-2.9)$ \\
\hline Hispanic & $4(8.5)$ & $0.6(0.2-1.7)$ & $0.4(0.1-1.4)$ & $11(23.4)$ & $1.0(0.5-2.1)$ & $0.9(0.4-2.4)$ & $4(8.5)$ & $0.6(0.2-1.8)$ & $0.4(0.1-1.2)$ \\
\hline Asian/Multiracial/Other & $8(5.7)$ & $0.4(0.2-0.8)^{*}$ & $0.3(0.1-0.8)^{*}$ & 15 (10.6) & $0.4(0.2-0.7)^{*}$ & $0.5(0.2-1.0)^{*}$ & $7(5.0)$ & $0.3(0.2-0.8)^{*}$ & $0.2(0.1-0.7)^{*}$ \\
\hline \multicolumn{10}{|l|}{ Parent demographics } \\
\hline \multicolumn{10}{|l|}{ Education } \\
\hline High school graduate or less & $3(4.7)$ & REF & - & $4(6.4)$ & REF & REF & $0(0)$ & NA & NA \\
\hline Some college or higher & $45(12.4)$ & $2.9(0.9-9.5)$ & - & 79 (21.6) & $\begin{array}{l}4.1 \\
(1.4-11.6)^{*}\end{array}$ & $\begin{array}{l}5.0 \\
(1.0-24.4)^{*}\end{array}$ & $42(11.4)$ & NA & NA \\
\hline \multicolumn{10}{|l|}{ Household income } \\
\hline$\leq \$ 75,000$ & $18(11.1)$ & REF & - & 31 (19.4) & REF & - & $16(9.9)$ & REF & - \\
\hline$>\$ 75,000$ & $33(12.2)$ & $1.1(0.6-2.0)$ & - & $52(19.1)$ & $1.0(0.6-1.6)$ & - & $30(11.0)$ & $1.1(0.6-2.1)$ & - \\
\hline \multicolumn{10}{|l|}{ Adolescent exposures } \\
\hline \multicolumn{10}{|l|}{ Witnessed $\geq 1$ disturbing events } \\
\hline Yes & $38(14.3)$ & $2.3(1.2-4.4)^{*}$ & $1.8(0.8-4.0)$ & $62(23.3)$ & $2.1(1.3-3.6)^{*}$ & $2.1(1.1-4.3)^{*}$ & $36(13.5)$ & $2.6(1.2-5.7)^{*}$ & $2.7(1.1-6.4)^{*}$ \\
\hline No & $13(6.8)$ & REF & REF & $24(12.5)$ & REF & REF & $10(5.2)$ & REF & REF \\
\hline \multicolumn{10}{|l|}{ Sustained injury on $9 / 11$} \\
\hline Yes & $2(7.4)$ & $0.6(0.1-2.7)$ & - & $5(18.5)$ & $1.0(0.4-2.7)$ & - & 0 & NA & NA \\
\hline No & 49 (11.4) & REF & - & $81(18.8)$ & REF & - & $46(10.7)$ & NA & NA \\
\hline \multicolumn{10}{|l|}{ Caught in dust cloud on $9 / 11$} \\
\hline Yes & $20(10.4)$ & $0.9(0.5-1.6)$ & - & $31(16.1)$ & $0.7(0.5-1.2)$ & - & $19(9.8)$ & $1.0(0.5-1.8)$ & - \\
\hline No & $31(11.7)$ & REF & - & $55(20.8)$ & REF & - & $27(10.2)$ & REF & - \\
\hline \multicolumn{10}{|l|}{ Family exposure } \\
\hline Yes & $21(13.1)$ & $1.4(0.8-2.5)$ & - & $37(23.3)$ & $1.6(1.0-2.5)$ & - & $18(11.3)$ & $1.2(0.7-2.3)$ & - \\
\hline No & $30(10.1)$ & REF & - & 49 (16.4) & REF & - & $28(9.4)$ & REF & - \\
\hline \multicolumn{10}{|l|}{ Parent mental health } \\
\hline$K 6 \geq 12$ & $5(9.6)$ & $0.8(0.3-2.2)$ & - & $9(17.3)$ & $0.9(0.4-1.9)$ & - & $5(9.6)$ & $0.9(0.4-2.5)$ & - \\
\hline $\mathrm{K} 6<12$ & $46(11.4)$ & REF & REF & 77 (19.1) & REF & REF & $41(10.2)$ & REF & REF \\
\hline Other trauma (not 9/11) & & & & & & & & & \\
\hline Yes & $12(17.7)$ & $1.9(0.9-3.8)$ & - & $18(26.5)$ & $1.7(0.9-3.0)$ & - & $11(16.4)$ & $2.0(0.9-4.1)$ & - \\
\hline No & 39 (10.3) & REF & REF & $68(17.9)$ & REF & REF & $35(9.2)$ & REF & REF \\
\hline Adolescent Health Care & & & & & & & & & \\
\hline $\begin{array}{l}\text { Treatment by a mental } \\
\text { health professional } \\
\text { (past } 12 \text { months) }\end{array}$ & & & & & & & & & \\
\hline Yes & $16(18.6)$ & $2.2(1.1-4.1)^{*}$ & $1.2(0.5-2.7)$ & $24(27.9)$ & $2.0(1.2-3.5)^{*}$ & $1.2(0.5-2.6)$ & $17(19.8)$ & $2.9(1.5-5.6)^{*}$ & $2.2(0.9-5.3)$ \\
\hline No & $34(9.6)$ & REF & REF & $58(16.3)$ & REF & REF & $28(7.8)$ & REF & REF \\
\hline $\begin{array}{l}\text { Treatment or counseling } \\
\text { for substance } \\
\text { use (since } 9 / 11 / 01 \text { ) }\end{array}$ & & & & & & & & & \\
\hline Yes & $1(9.1)$ & $0.8(0.1-6.0)$ & - & $2(18.2)$ & $0.9(0.2-4.4)$ & - & $0(0)$ & $\mathrm{N} / \mathrm{A}$ & $\mathrm{N} / \mathrm{A}$ \\
\hline No & $50(11.7)$ & REF & REF & $82(19.2)$ & REF & REF & $46(10.8)$ & $\mathrm{N} / \mathrm{A}$ & N/A \\
\hline $\begin{array}{l}\text { Adolescent Screening Measures } \\
\text { SDQ }\end{array}$ & & & & & & & & & \\
\hline Abnormal/borderline & 8 (14.8) & $1.5(0.7-3.4)$ & $0.6(0.2-2.1)$ & $14(25.5)$ & $1.6(0.8-3.0)$ & $1.2(0.4-3.4)$ & 10 (17.9) & $2.2(1.1-4.8)^{*}$ & $0.9(0.3-2.9)$ \\
\hline Normal & $41(10.5)$ & REF & REF & 70 (17.9) & REF & REF & $35(9.0)$ & REF & REF \\
\hline PTSD & & & & & & & & & \\
\hline Yes & $1(7.7)$ & $0.7(0.1-5.2)$ & - & $3(23.1)$ & $1.3(0.4-4.9)$ & - & $2(15.4)$ & $1.7(0.4-7.7)$ & - \\
\hline No & $50(11.2)$ & REF & - & $83(18.7)$ & REF & - & $44(9.9)$ & REF & - \\
\hline School functioning (mean $[S D]$ ) & $\begin{array}{l}67.0 \\
(17.6)\end{array}$ & $\begin{array}{c}0.97 \\
(0.96-0.98)^{*}\end{array}$ & $\begin{array}{c}0.97 \\
(0.95-0.99)^{*}\end{array}$ & $\begin{array}{c}69.8 \\
(18.7)\end{array}$ & $\begin{array}{c}0.98 \\
(0.96-0.99)^{*}\end{array}$ & $\begin{array}{c}0.98 \\
(0.97-0.99)^{*}\end{array}$ & $\begin{array}{c}64.8 \\
(17.6)\end{array}$ & $\begin{array}{c}0.96 \\
(0.95-0.98)^{*}\end{array}$ & $\begin{array}{c}0.96 \\
(0.95-0.99)^{*}\end{array}$ \\
\hline $\begin{array}{l}\text { Adolescents } \geq 5 \text { years } \\
\quad \text { of age on } 9 / 11(\mathrm{~N}=174) \\
\text { Fear for personal safety on } 9 / 11\end{array}$ & & & & & & & & & \\
\hline Yes & $12(42.9)$ & $3.8(1.5-9.4)^{*}$ & $2.7(1.1-7.4)^{*}$ & 20 (71.4) & $4.4(1.7-10.9)^{*}$ & $3.3(1.2-8.7)^{*}$ & 13 (46.4) & $3.8(1.5-9.3)^{*}$ & $2.7(1.1-7.2)^{*}$ \\
\hline No & 16 (16.7) & REF & REF & 35 (36.5) & REF & REF & 18 (18.8) & REF & REF \\
\hline
\end{tabular}

Note. $\mathrm{cOR}=$ crude odds ratio; $\mathrm{aOR}=$ adjusted odds ratio; $\mathrm{REF}=$ reference; $\mathrm{SDQ}=$ Strengths and Difficulties Questionnaire.

${ }^{\mathrm{a}}$ May not equal $100 \%$ because of missing values.

${ }^{\mathrm{b}}$ Adjusted for only variables significant at $p<.05$ in the COR plus gender and SDQ.

${ }^{*} p \leq .05$. 
school functioning score of 9/11-exposed adolescents was similar to published reports on the general population (Varni et al., 2006; Varni, Burwinkle, Seid, \& Skarr, 2003). We found that an increase in school functioning was associated with a decrease in the odds of ever having smoked cigarettes, drank, or used marijuana. Given that academic achievement is an important predictor of successful transition to young adulthood, these findings call for developing case identification procedures to recognize adolescents with increased substance use for possible intervention, particularly after a disaster.

Substance use in adults often develops as a coping strategy for relieving traumatic memories, sleep disturbances, and other PTSD symptoms (Brown \& Wolfe, 1994; Chilcoat \& Breslau, 1998; Saladin, Brady, Dansky, \& Kilpatrick, 1995; Welch et al., 2014). Although this hypothesis has not been widely tested among adolescents (Joshi \& O’Donnell, 2003; Schiff et al., 2006), it does suggest that youths may turn to alcohol and other drugs to manage the intense flood of emotions and traumatic reminders associated with traumatic stress or PTSD, or to numb themselves from the experience of any intense emotion, whether positive or negative.

\section{Limitations}

Our results may not be generalizable to all NYC youths, as we studied a highly exposed population. We used a checklist-the DPS-to assess PTSD rather than conduct a clinical diagnostic interview. Although the DPS is a widely used survey instrument, we can only interpret self-report of symptoms as probable PTSD and we may have overestimated symptom prevalence. Using this instrument, we found a small proportion of adolescents (2.6\%) screened positive for PTSD (2.8\%). Normative prevalence data for PTSD among adolescents in New York City prior to 9/11 are limited, but performance testing of the DISC Version 2.3 in the early 1990s in four cities, including New York City, found a prevalence of 1.6\% for any anxiety disorder using DSM-III-R criteria with diagnostic-specific impairment criteria (Shaffer et al., 1996). This relatively small number of adolescents with PTSD may play a factor on why we did not find an association between PTSD and substance use. Our measure of binge drinking (five or more drinks in a row) used a threshold that was appropriate only for 16- to 17-yearold males. The threshold is lower for females under 18 and males ages nine to 13 (three drinks) and males ages 14 to 15 (four drinks; Centers for Disease Control and Prevention, 2014a; National Institute on Alcohol Abuse and Alcoholism, 2015). As such, we may have underestimated the prevalence of binge drinking in this population. Despite procedures to ensure privacy, adolescents may have been afraid that their parents would see their responses, which may have led to an underreporting of their substance use. Adolescents who did not complete Wave 3 differed significantly on race and parent income in 2002. This may have biased our results and could be one potential explanation for why there was no association found between these factors and risk behaviors. It is not possible to determine whether the adolescent report of fearing for personal safety or safety of loved ones on 9/11 are true recollections or reflection of their own emotions rather than those from their family environment which may have developed later. Regardless, these factors are important correlates of risk behaviors and should be targeted as potential areas of intervention. In addition, we did not collect information on other variables known to predict adolescent substance use, including parental substance use or attitudes toward substance use, peer influence, or ease of availability of substances, which may make it difficult to ascertain how much of the association observed is unique to the adolescent's $9 / 11$ experience.

\section{Conclusions}

These findings have both clinical and policy relevance, especially in planning for future large-scale traumatic events. Intervention and education for adolescents, particularly if focused on substance use and coping strategies, may be warranted after large-scale disasters in order to increase adolescents' capacity to respond to crises. Moreover, our findings suggest that schoolteachers and counselors should be aware that impairments in school functioning, such as poor grades and attendance or inattentiveness, could be reflections of substance use, both in disaster- and non-disaster-exposed adolescents. Our results also suggest that monitoring of adolescents should continue beyond the immediate post-disaster period as our respondents reported substance use related to $9 / 11$ exposures 10 to 11 years after the terrorist attack.

\section{Funding}

This study was supported by Cooperative Agreement Numbers $5 \mathrm{U} 50 / \mathrm{OH} 009739$ and 1E11/OH009630 from the National Institute for Occupational Safety and Health (NIOSH) of the Centers for Disease Control and Prevention (CDC); U50/ ATU272750 from the Agency for Toxic Substances and Disease Registry (ATSDR), CDC, which included support from the National Center for Environmental Health, CDC; and by the New York City Department of Health and Mental Hygiene (NYC DOHMH). Its contents are solely the responsibility of the authors and do not necessarily represent the official views of NIOSH-CDC. 


\section{References}

Adams, R. E., Boscarino, J. A., \& Galea, S. (2006). Alcohol use, mental health status and psychological well-being 2 years after the World Trade Center attacks in New York City. The American Journal of Drug and Alcohol Abuse, 32(2), 203-224.

Boscarino, J. A., Adams, R. E., \& Galea, S. (2006). Alcohol use in New York after the terrorist attacks: A study of the effects of psychological trauma on drinking behavior. [Research Support, N.I.H., Extramural]. Addictive Behaviors, 31(4), 606-621.

Bourdon, K. H., Goodman, R., Rae, D. S., Simpson, G., \& Koretz, D. S. (2005). The Strengths and Difficulties Questionnaire: U.S. normative data and psychometric properties. Journal of the American Academy of Child and Adolescent Psychiatry, 44(6), 557-564.

Brackbill, R. M., Hadler, J. L., DiGrande, L., Ekenga, C. C., Farfel, M. R., Friedman, S.,... Thorpe, L. E. (2009). Asthma and posttraumatic stress symptoms 5 to 6 years following exposure to the World Trade Center terrorist attack. [Research Support, Non-U.S. Gov't Research Support, U.S. Gov't, P.H.S.]. JAMA, 302(5), 502-516.

Brown, P. J., \& Wolfe, J. (1994). Substance abuse and posttraumatic stress disorder comorbidity. Drug and Alcohol Dependence, 35(1), 51-59.

Centers for Disease Control and Prevention. (2014a). Fact sheets-underage drinking. Retrieved from http://www.cdc. gov/alcohol/fact-sheets/underage-drinking.htm

Centers for Disease Control and Prevention. (2014b). Youth Risk Behavior Surveillance System (YRBSS)-2011. Retrieved http://www.cdc.gov/HealthyYouth/yrbs/index. htm

Centers for Disease Control and Prevention. (2015). Youth and tobacco use. Retrieved from http://www.cdc.gov/tobacco/data_sta tistics/fact_sheets/youth_data/tobacco_use/index.htm

Chemtob, C. M., Nomura, Y., Josephson, L., Adams, R. E., \& Sederer, L. (2009). Substance use and functional impairment among adolescents directly exposed to the 2001 World Trade Center attacks. Disasters, 33(3), 337-352.

Chilcoat, H. D., \& Breslau, N. (1998). Investigations of causal pathways between PTSD and drug use disorders. Addictive Behaviors, 23(6), 827-840.

Clark, D. B., Lesnick, L., \& Hegedus, A. M. (1997). Traumas and other adverse life events in adolescents with alcohol abuse and dependence. Journal of the American Academy of Child and Adolescent Psychiatry, 36(12), 1744-1751.

Fairclough, D. L. (2002). Design and analysis of quality of life studies in clinical trials: Interdisciplinary statistics. New York, NY: Chapman \& Hall/CRC.

Fairclough, D. L., \& Cella, D. F. (1996). Functional Assessment of Cancer Therapy (FACT-G): Non-response to individual questions. Quality of Life Research, 5(3), 321-329.

Giaconia, R. M., Reinherz, H. Z., Hauf, A. C., Paradis, A. D., Wasserman, M. S., \& Langhammer, D. M. (2000). Comorbidity of substance use and post-traumatic stress disorders in a community sample of adolescents. American Journal of Orthopsychiatry, 70(2), 253-262.

Goodman, A., Lamping, D. L., \& Ploubidis, G. B. (2010). When to use broader internalising and externalising subscales instead of the hypothesised five subscales on the Strengths and Difficulties Questionnaire (SDQ): Data from British parents, teachers and children. Journal of Abnormal Child Psychology, 38(8), 1179-1191.

Goodman, R., Ford, T., Simmons, H., Gatward, R., \& Meltzer, H. (2000). Using the Strengths and Difficulties Questionnaire (SDQ) to screen for child psychiatric disorders in a community sample. British Journal of Psychiatry, 177, 534-539.

Grant, B. F., \& Dawson, D. A. (1997). Age at onset of alcohol use and its association with DSM-IV alcohol abuse and dependence: Results from the National Longitudinal Alcohol Epidemiologic Survey. Journal of Substance Abuse Treatment, 9, 103-110.

Grant, B. F., Stinson, F. S., \& Harford, T. C. (2001). Age at onset of alcohol use and DSM-IV alcohol abuse and dependence: A 12-year follow-up. Journal of Substance Abuse Treatment, 13(4), 493-504.

Hawkins, J. D., Catalano, R. F., \& Miller, J. Y. (1992). Risk and protective factors for alcohol and other drug problems in adolescence and early adulthood: Implications for substance abuse prevention. Psychological Bulletin, 112(1), 64-105.

Hoven, C. W., Duarte, C. S., Lucas, C. P., Wu, P., Mandell, D. J., Goodwin, R. D.,... Susser, E. (2005). Psychopathology among New York city public school children 6 months after September 11. Archives of General Psychiatry, 62(5), 545552.

Joshi, P. T., \& O’Donnell, D. A. (2003). Consequences of child exposure to war and terrorism. Clinical Child and Family Psychology Review, 6(4), 275-292.

Kessler, R. C., Andrews, G., Colpe, L. J., Hiripi, E., Mroczek, D. K., Normand, S. L.,... Zaslavsky, A. M. (2002). Short screening scales to monitor population prevalences and trends in non-specific psychological distress. Psychological Medicine, 32(6), 959-976.

Lucas, C. P., Zhang, H., Fisher, P. W., Shaffer, D., Regier, D. A., Narrow, W. E.,... Friman, P. (2001). The DISC Predictive Scales (DPS): Efficiently screening for diagnoses. Journal of the American Academy of Child and Adolescent Psychiatry, 40(4), 443-449.

McLeod, J. D., Uemura, R., \& Rohrman, S. (2012). Adolescent mental health, behavior problems, and academic achievement. [Research Support, N.I.H., Extramural]. Journal of Health and Social Behavior, 53(4), 482-497.

Murphy, J., Brackbill, R. M., Thalji, L., Dolan, M., Pulliam, P., \& Walker, D. J. (2007). Measuring and maximizing coverage in the World Trade Center Health Registry. [Research Support, U.S. Gov't, P.H.S.]. Statistics in Medicine, 26(8), 1688-1701.

National Institute on Alcohol Abuse and Alcoholism. (2015). Underage drinking. Retrieved from http://www.niaaa.nih. gov/alcohol-health/special-populations-co-occurring-disor ders/underage-drinking

Perkonigg, A., Kessler, R. C., Storz, S., \& Wittchen, H. U. (2000). Traumatic events and post-traumatic stress disorder in the community: Prevalence, risk factors and comorbidity. Acta Psychiatrica Scandinavica, 101(1), 46-59.

Richter, J., Sagatun, A., Heyerdahl, S., Oppedal, B., \& Roysamb, E. (2011). The Strengths and Difficulties Questionnaire (SDQ) - self-report. An analysis of its structure in a multiethnic urban adolescent sample. Journal of Child Psychology and Psychiatry, 52(9), 1002-1011.

Saladin, M. E., Brady, K. T., Dansky, B. S., \& Kilpatrick, D. G. (1995). Understanding comorbidity between PTSD and 
substance use disorders: Two preliminary investigations. Addictive Behaviors, 20(5), 643-655.

Schiff, M., Benbenishty, R., McKay, M., Devoe, E., Liu, X., \& Hasin, D. (2006). Exposure to terrorism and Israeli youths' psychological distress and alcohol use: An exploratory study. The American Journal on Addictions, 15(3), 220-226.

Shaffer, D., Fisher, P., Dulcan, M. K., Davies, M., Piacentini, J., Schwab-Stone, M. E.,... Regier, D. A. (1996). The NIMH Diagnostic Interview Schedule for Children Version 2.3 (DISC-2.3): Description, acceptability, prevalence rates, and performance in the MECA Study. Methods for the Epidemiology of Child and Adolescent Mental Disorders Study. [Research Support, U.S. Gov't, P.H.S.]. Journal of the American Academy of Child and Adolescent Psychiatry, 35(7), 865-877.

Shaffer, D., Fisher, P., Lucas, C. P., Dulcan, M. K., \& SchwabStone, M. E. (2000). NIMH Diagnostic Interview Schedule for Children Version IV (NIMH DISC-IV): Description, differences from previous versions, and reliability of some common diagnoses. Journal of the American Academy of Child and Adolescent Psychiatry, 39(1), 28-38.

Staff, J., Patrick, M. E., Loken, E., \& Maggs, J. L. (2008). Teenage alcohol use and educational attainment. Journal of Studies on Alcohol and Drugs, 69(6), 848-858.

Thomas, P. A., Brackbill, R., Thalji, L., DiGrande, L., Campolucci, S., Thorpe, L.,... Henning, K. (2008). Respiratory and other health effects reported in children exposed to the World Trade Center disaster of 11 September 2001. Environmental Health Perspectives, 116(10), 1383-1390.

Varni, J. W., Burwinkle, T. M., \& Seid, M. (2006). The PedsQL 4.0 as a school population health measure:
Feasibility, reliability, and validity. Quality of Life Research, 15(2), 203-215.

Varni, J. W., Burwinkle, T. M., Seid, M., \& Skarr, D. (2003). The PedsQL 4.0 as a pediatric population health measure: Feasibility, reliability, and validity. Ambulatory Pediatrics, 3 (6), 329-341.

Vlahov, D., Galea, S., Ahern, J., Resnick, H., \& Kilpatrick, D. (2004). Sustained increased consumption of cigarettes, alcohol, and marijuana among Manhattan residents after September 11, 2001. American Journal of Public Health, 94(2), 253-254.

Vlahov, D., Galea, S., Resnick, H., Ahern, J., Boscarino, J. A., Bucuvalas, M.,... Kilpatrick, D. (2002). Increased use of cigarettes, alcohol, and marijuana among Manhattan, New York, residents after the September 11th terrorist attacks. [Research Support, Non-U.S. Gov't Research Support, U.S. Gov't, P.H.S.]. American Journal of Epidemiology, 155(11), 988-996.

Ware, J. E. (1993). SF-36 health survey: Manual and interpretation guide. Boston, MA: The Health Institute.

Welch, A. E., Caramanica, K., Maslow, C. B., Cone, J. E., Farfel, M. R., Keyes, K. M.,... Hasin, D. S. (2014). Frequent binge drinking five to six years after exposure to 9/11: Findings from the World Trade Center Health Registry. Drug and Alcohol Dependence, 140, 1-7.

Wu, P., Duarte, C. S., Mandell, D. J., Fan, B., Liu, X., Fuller, C. J.,... Hoven, C. W. (2006). Exposure to the World Trade Center attack and the use of cigarettes and alcohol among New York City public high-school students. American Journal of Public Health, 96(5), 804-807. 